\title{
Weight Estimation of Asian Sea Bass (Lates calcarifer) Comparing Whole Body with and without Fins using Computer Vision Technique
}

\author{
Roongparit JONGJARAUNSUK and Wara TAPARHUDEE ${ }^{*}$ \\ Department of Aquaculture, Faculty of Fisheries, Kasetsart University, Bangkok 10900, Thailand
}

('Corresponding author's e-mail: ffiswrt@ku.ac.th)

Received: 10 February 2020, Revised: 14 December 2020, Accepted: 18 December 2020

\begin{abstract}
An optimal model to evaluate the weight of the whole body of Asian sea bass with and without fins was generated using computer vision image processing techniques. Image data of 25 fish randomly selected were collected every week for one month. The data were divided into two sets by means of a 40 $60 \%$ split-test, $40 \%$ (10 fish; 100 images) were used as training data and $60 \%$ (15 fish; 150 images) were used as out-samples or validation data. The model using fish images without fins gave a higher average and total coefficient of determination $\left(\mathrm{N}_{150} \mathrm{R}^{2}=0.77 \pm 0.10, \mathrm{~N}_{600} \mathrm{R}^{2}=0.96\right)$ than using images with fins $\left(\mathrm{N}_{150} \mathrm{R}^{2}=0.24 \pm 0.20, \mathrm{~N}_{600} \mathrm{R}^{2} 0.63\right)$. Errors as root mean square error (RMSE), mean absolute error (MAE), mean absolute relative error (MARE), maximum absolute error (MXAE), and maximum relative error (MXRE) were compared using mathematical models. Results showed that the model using fish images without fins recorded fewer errors, with average values of $9.19 \pm 3.74 \mathrm{~g}, 6.06 \pm 3.64 \mathrm{~g}, 5.18 \pm$ $3.08 \%, 8.87 \pm 3.26 \mathrm{~g}$ and $0.12 \pm 0.12 \%$, respectively compared with fish images with fins at $12.35 \pm$ $4.45 \mathrm{~g}, 11.26 \pm 3.61 \mathrm{~g}, 9.69 \pm 2.94 \%, 11.50 \pm 4.71 \mathrm{~g}$ and $0.14 \pm 0.11 \%$, respectively. Comparison between models, with and without fins, and normal manual measurement methods found no statistically significant differences $(\mathrm{P}>0.05)$. Therefore, this technique may be applied for weight estimation in real pond conditions to give advantages of reduced time, stress and injury, with minimal interference in fish feeding compared to physical capture and weighing.
\end{abstract}

Keywords: Computer vision technique, Fin, Weight estimation, Whole body, Asian sea bass, Image processing

\section{Introduction}

The Asian sea bass, also known as Barramundi (Lates calcarifer), is the predominant fish species in coastal aquaculture in Thailand. It is also an important fishery commodity representing $10 \%$ of all seafood production. Asian sea bass production increased by $87.33 \%$, from 2,591 tons in 1992 to 20,453 tons in 2017, according to the Thailand Department of Fisheries [1].

Fish weight estimation is important for sales data management of aquaculture operations to allow farmers to apply a suitable amount of feed each day. This process is usually carried out by sampling fish from ponds, cages, or tanks using a scoop net and weighing on a scale. This method causes stress and injury to the fish and is also labor-intensive [2]. Fish that are stressed often do not feed for several days resulting in reduced growth rates. Thus, fish farmers prefer to use their experience to estimate the weight of fishes to determine feed amounts, which can result in high errors [3,4].

To resolve this problem, many researchers applied image processing techniques combined with computer vision to estimate the weight of fish and other aquatic animals. For example, [5] applied computer technology to assess the number and size of tuna in the sea. At the same time, [6] developed a simple image processing technique using linear equation transformation and Move-tr/3DTM software for three-dimensional measurement of bluefin tuna reared freely in a cage culture system. [7] developed a 
prototype to measure rainbow trout length, using an online vision component to detect, capture and process downward-view images when fish passed below the camera.

However, for weight assessment, the specificities of these techniques depend on the types of fish. [8] found that removing the fins and tail did not improve prediction accuracy for weight estimation of Alaskan pollock, while [9] reported that a weight estimation model gave better results when removing the tail fin of Jade perch. This finding concurred with the results of [10], who studied sea bass weight estimation. The shapes of fish fins may change as a result of wounds or natural erosion, and catching the fish to take a photo from the side for analysis may not be suitable in the farm environment. Therefore, the objective of this study was to determine an optimal model for evaluating the weight of sea bass using computer vision image processing techniques of photos taken at a high angle above the water surface in real conditions without catching the fish.

\section{Materials and methods}

Fish sample and facilities

All experiments were conducted at the Freshwater Aquaculture Laboratory, Faculty of Fisheries, Kasetsart University, Bang Khen Campus. One hundred sea bass, weighing on average $30 \mathrm{~g}$ each were bought from a private fish farm and stocked in two 1,000-L fiberglass tanks (50 fish per tank). The fish were fed at least $35 \%$ protein of floating pellet feed twice a day (0800 h and $1700 \mathrm{~h})$ by hand until satiation using a flow-through water system. Each tank contained three air stones, and water quality was controlled at a suitable condition for raising sea bass with dissolved oxygen (DO), water temperature, $\mathrm{pH}$, total ammonia-nitrogen (TAN), and nitrite-nitrogen $\left(\mathrm{NO}_{2}-\mathrm{N}\right)$ at levels greater than $4 \mathrm{mg} / \mathrm{L}, 26-32$ degrees Celsius, $7.5-8.5$, less than $1 \mathrm{mg} / \mathrm{L}$ and less than $1 \mathrm{mg} / \mathrm{L}$, respectively [11,12]. Fish acclimation was conducted until the average fish weight was between 80 and $100 \mathrm{~g}$.

\section{Data collection}

Data collection was performed 4 times (every week for one month). The first data collection was conducted when the average fish weight was between 80 and 100 g. Feeding was withdrawn one day before the experiment. Twenty-five healthy fish (observed from outside appearance, with normal swimming and no wounds on the body) were randomly sampled. Each fish was placed in a $50 \times 80 \times 20 \mathrm{~cm}^{3}$ fiberglass tank containing 80 liters of water, and tricaine methane sulfonate (MS-222) was added at 20 $\mathrm{mg} / \mathrm{L}$ to decrease body movement. The fish was then transferred to a white rectangular plastic box size $28 \times 42.5 \times 9.5 \mathrm{~cm}^{3}$ with a water depth of $7 \mathrm{~cm}$ and photographed at a distance of $80 \mathrm{~cm}$ from the lens to the object (fish) following the method of [9] (Figure 1). An Olympus EM 10 Mark II (Olympus Corporation, Tokyo, Japan) camera was used and pictures were taken at focal length $14 \mathrm{~mm}$, exposure $1 / 40 \mathrm{sec}$, ISO 1600 and a resolution of $4,608 \times 2,592$ pixels. Each fish was photographed ten times and then weighed using a CST-CDR-3 scale before returning to an 80-L recuperation tank fully aerated by a sand stone. After recovery, the fish was returned to the experimental tank and the process was repeated after 7 days.

\section{Image processing techniques}

Fish images were processed using the Image J Java-based image processing program developed at the National Institute of Health (NIH), USA. Image-J is freely available as an open source, multithreaded independent platform and can be utilized to develop user-coded plugins to suit the specific requirement of any conceived application [13]. The computer used was an Acer Aspire E 15 (Windows 10 Pro, AMD FX-9800P Radeon R7, 12GB Compute Core 4G + 8G, 2.70 GHz, memory (RAM) 8 GB, and 64-bit operating system).

The procedure to locate the image area to evaluate fish weights began by choosing the fish image to be analyzed. Then, the 'polygon' function was selected and the mouse was manually clicked around the desired area (around the fish). Each sampled fish was marked out as the whole body with and without fins five times. Then, foreground objects were pulled from the background to make the outline of the fish black and the background white (image binarizing by thresholding algorithm). Areas of the fish images 
were determined by the 'analyzing particles' function to calculate total pixels in a specific area (Figure 2).
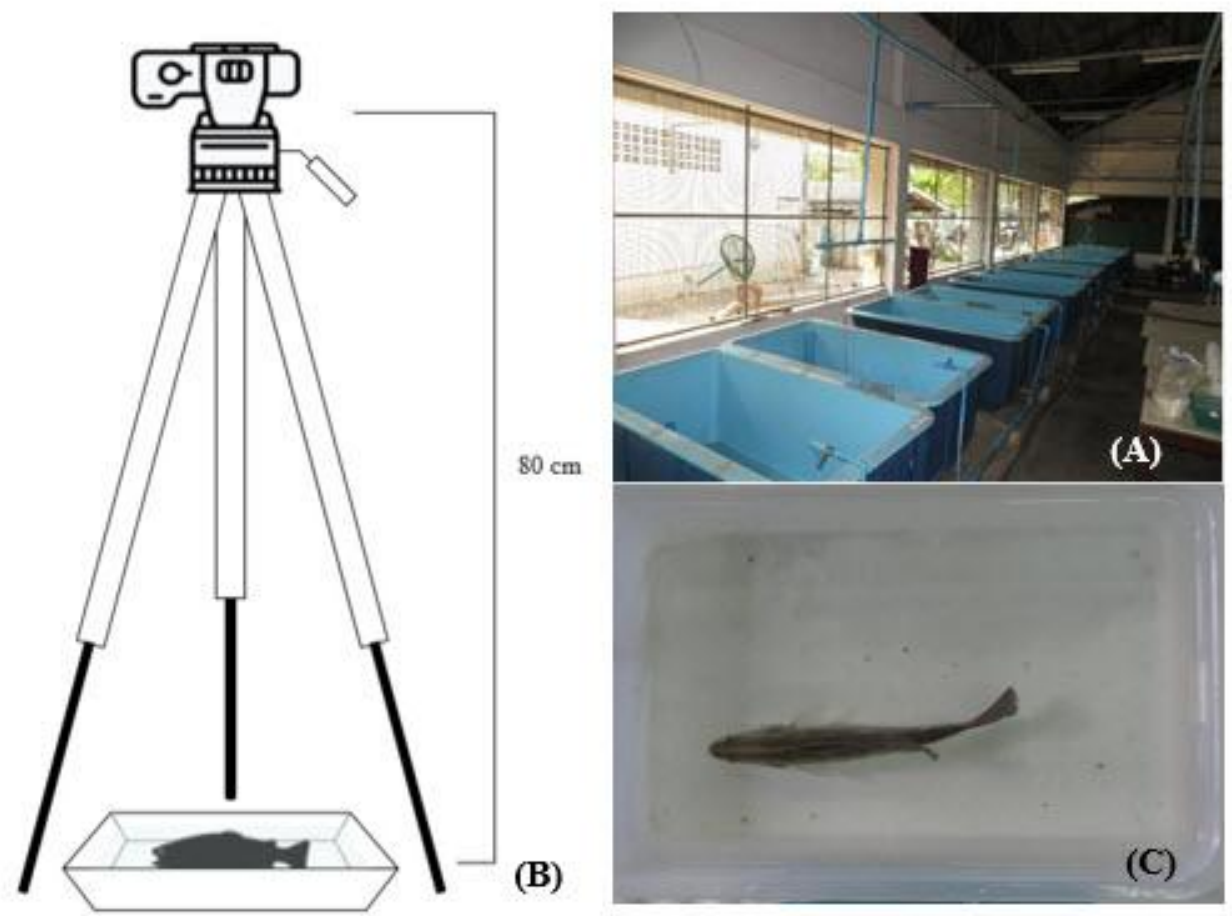

Figure 1 (A) Experimental tanks with a flow-through system, (B) Digital camera used at a height of 80 $\mathrm{cm}$, and (C) Sampled fish image.

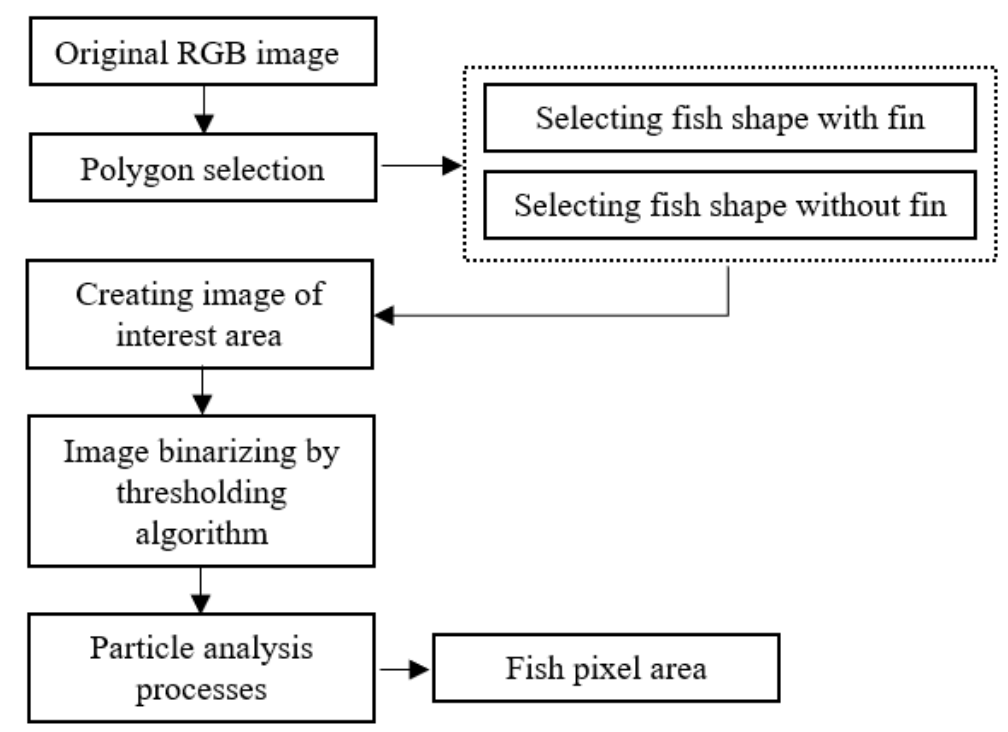

Figure 2 Analysis procedure using Image J. 


\section{Creating equations to evaluate fish weight from images}

The relationship between the pixel area $(A)$ and weight $(W)$ of each fish was generated using a linear regression model. $[9,14]$ reported that this model was generally applied for fish weight assessment using pixel areas as the following details:

$W=\mathrm{a}+\mathrm{b} A$

where $W$ is the body weight (g), $A$ is the pixel area of the fish (pixels), and a and $\mathrm{b}$ are constants.

The image data of one fish was analyzed using 10 images (five images for whole body image areas and another five images for without fins image areas). To reduce the over-fitting problem, fish image data were divided into two sets by a 40 - $60 \%$ split-test; $40 \%$ (10 fish; 100 images) were used as training data and $60 \%$ (15 fish; 150 images) were used as out-samples or validation data, as shown in Figure 3.

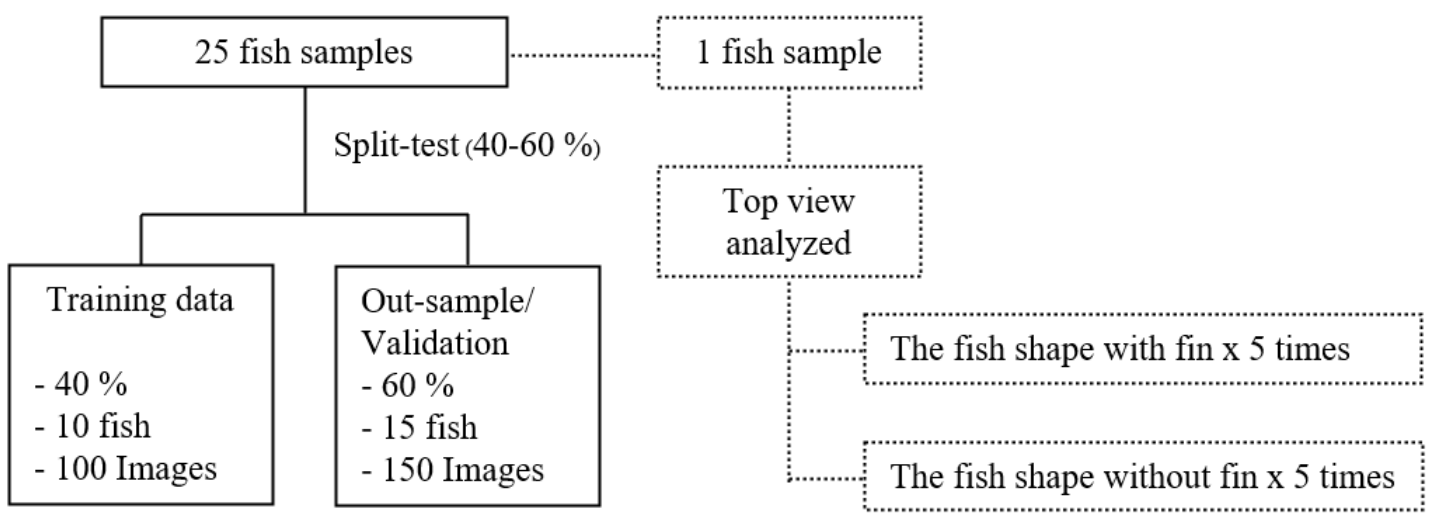

Figure 3 Testing procedure for fish sampling.

\section{Data analysis}

First, the training data set was used to create relationships between pixel areas and fish weights to determine the coefficient of determination $\left(\mathrm{R}^{2}\right)$ of the linear model between the model generated from the whole body of the fish image area (with fins) and the model generated from the fish image area (without fins) (Figure 4). Then, the created model was examined for the validation data set. Performance of the model was tested using mathematical models for error analysis, i.e. root mean square error (RMSE), mean absolute error (MAE), mean absolute relative error (MARE), maximum absolute error (MXAE) and maximum relative error (MXRE) as shown by the equations below.

Root mean square error (RMSE):

$\mathrm{RMSE}=\sqrt{\frac{\sum_{N}^{i=1}\left[W_{\text {estimated. } i}-W_{\text {measured. } i] 2}\right.}{N}}$

Mean absolute error (MAE):

$\mathrm{MAE}=\frac{\sum_{N}^{i=1}\left|W_{\text {estimated. } i}-W_{\text {measured. } i}\right|}{N}$ 
Mean absolute relative error (MARE):

MARE $=\frac{\sum_{N}^{i=1}\left|W_{\text {estimated } . i}-W_{\text {measured. } i}\right| / W_{\text {measured. } i}}{N} \times 100$

Maximum absolute error (MXAE):

$\mathrm{MXAE}=\max _{i=1}^{N}\left(\left|W_{\text {estimated.i }}-W_{\text {measured.i }}\right|\right)$

Maximum relative error (MXRE):

$\operatorname{MXRE}=\max _{i=1}^{N}\left(\frac{\left|W_{\text {estimated. } i}-W_{\text {measured. } i}\right|}{W_{\text {measured.i }}}\right)$
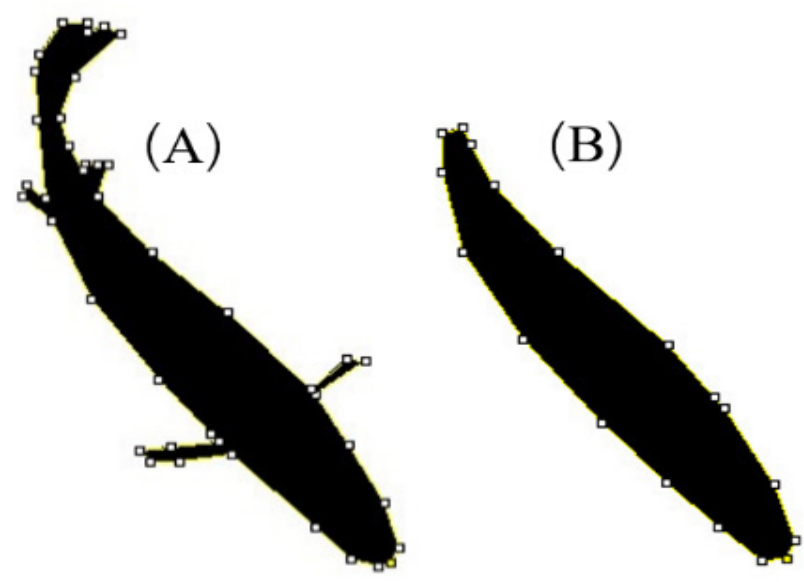

Figure 4 Fish image of the whole body area with fins (A) and without fins (B).

The results of using the whole body and without fin images were compared using the average coefficient of determination from the validation dataset generated from 15 fish (150 images) from every test $\left(\mathrm{N}_{150} \mathrm{R}^{2}\right)$, and the coefficient of determination from the total validation dataset generated from 60 fish (600 images) from all tests $\left(\mathrm{N}_{600} \mathrm{R}^{2}\right)$ using mathematical models (RMSE, MAE, MARE, MXAE, and MXRE) of the validation dataset. The mean difference was compared using the independent sample T-test at $95 \%$ confidence level and the IBM SPSS Statistics Base 24.0 for Windows.

\section{Results and discussion}

Comparison of error between the model of whole body of fish with fins and without fins

The training dataset of the four tests gave the mean predictable coefficient $\left(\mathrm{R}^{2}\right)$ of the linear mathematical model of the whole body as $0.76 \pm 0.13$, while that of the without fins model was $0.88 \pm$ 0.07 (Table 1). 
Table 1 Coefficients of mathematical models fitted by regression analysis on fish shape with and without fins (training dataset).

\begin{tabular}{cclcccccc}
\hline \multirow{2}{*}{ Test } & $\begin{array}{c}\text { FW range } \\
(\mathbf{g} / \text { fish })\end{array}$ & \multirow{2}{*}{ Equation } & \multicolumn{3}{c}{ Model coefficients with fins } & \multicolumn{3}{c}{ Model coefficients without fins } \\
\cline { 5 - 8 } & $80-100$ & Linear & 0.0013 & 24.414 & 0.90 & 0.0024 & 79.028 & 0.94 \\
& $>100-110$ & Linear & 0.0012 & 23.816 & 0.80 & 0.0005 & 53.542 & 0.82 \\
2 & $>110-130$ & Linear & 0.0001 & 99.802 & 0.59 & 0.0008 & 42.272 & 0.93 \\
3 & $>130-150$ & Linear & 0.0004 & 85.727 & 0.76 & 0.0005 & 85.018 & 0.82 \\
4 & Mean & & & 0.76 & & 0.88 \\
\hline & SD & & & 0.13 & & $\mathbf{R}^{\mathbf{2}}$ & 0.07 \\
\hline
\end{tabular}

*Note: $\mathrm{FW}=$ fish weight $(\mathrm{g} /$ fish. $)$

Validation datasets of the whole body images examined with mathematical models RMSE, MAE, MARE, MXAE and MXRE gave $12.35 \pm 4.45 \mathrm{~g}, 11.26 \pm 3.61 \mathrm{~g}, 9.69 \pm 2.94 \% 11.50 \pm 4.71 \mathrm{~g}$ and $0.14 \pm$ $0.11 \%$, with coefficient of determination $\left(\mathrm{R}^{2}\right)$ of $0.24 \pm 0.20$ (Table 2). For fish without fin images, the values were $9.19 \pm 3.74 \mathrm{~g}, 6.06 \pm 3.64 \mathrm{~g}, 5.18 \pm 3.08 \mathrm{~g}, 8.87 \pm 3.26 \mathrm{~g}, 0.12 . \pm 0.12$ and $0.77 \pm 0.10$, respectively (Table 3).

Table 2 Error in estimation of Asian sea bass (Lates calcarifer) weight and related statistical values in validation datasets using fish shape with fins.

\begin{tabular}{ccccccccc}
\hline Test & $\begin{array}{c}\text { FW range } \\
(\mathbf{g} / \text { fish) }\end{array}$ & Equation & $\begin{array}{c}\text { RMSE } \\
(\mathbf{g})\end{array}$ & $\begin{array}{c}\text { MAE } \\
\mathbf{( g )}\end{array}$ & $\begin{array}{c}\text { MARE } \\
\mathbf{( \% )}\end{array}$ & $\begin{array}{c}\text { MXAE } \\
\mathbf{( g )}\end{array}$ & $\begin{array}{c}\text { MXRE } \\
(\mathbf{\%})\end{array}$ & \multirow{2}{*}{$\mathbf{R}^{\mathbf{2}}$} \\
\hline 1 & $80-100$ & Linear & 7.21 & 6.68 & 7.24 & 5.20 & 0.05 & 0.38 \\
2 & $>100-110$ & Linear & 17.68 & 14.94 & 13.94 & 11.16 & 0.10 & 0.02 \\
3 & $>110-130$ & Linear & 10.76 & 10.24 & 8.45 & 13.27 & 0.11 & 0.14 \\
4 & $>130-150$ & Linear & 13.76 & 13.16 & 9.13 & 16.35 & 0.29 & 0.44 \\
\hline & & Mean & 12.35 & 11.26 & 9.69 & 11.50 & 0.14 & 0.24 \\
& & SD & 4.45 & 3.61 & 2.94 & 4.71 & 0.11 & 0.20 \\
\hline
\end{tabular}

*Note: $\mathrm{FW}=$ fish weight $(\mathrm{g} /$ fish $)$

Table 3 Error in estimation of Asian sea bass (Lates calcarifer) weight and related statistical value in validation datasets using fish shape without fins.

\begin{tabular}{ccccccccc}
\hline \multirow{2}{*}{ Test } & $\begin{array}{c}\text { FW range } \\
(\mathbf{g} / \mathbf{f i s h})\end{array}$ & Equation & $\begin{array}{c}\text { RMSE } \\
(\mathbf{g})\end{array}$ & $\begin{array}{c}\text { MAE } \\
\mathbf{( g )}\end{array}$ & $\begin{array}{c}\text { MARE } \\
(\mathbf{\%})\end{array}$ & $\begin{array}{c}\text { MXAE } \\
(\mathbf{g})\end{array}$ & $\begin{array}{c}\text { MXRE } \\
\mathbf{( \% )}\end{array}$ & $\mathbf{R}^{\mathbf{2}}$ \\
\hline 1 & $80-100$ & Linear & 4.10 & 2.87 & 3.13 & 7.16 & 0.02 & 0.83 \\
2 & $>100-110$ & Linear & 12.85 & 9.87 & 9.22 & 10.29 & 0.13 & 0.62 \\
3 & $>110-130$ & Linear & 9.04 & 3.01 & 2.46 & 5.35 & 0.04 & 0.80 \\
4 & $>130-150$ & Linear & 10.78 & 8.48 & 5.89 & 12.69 & 0.28 & 0.83 \\
\hline & & Mean & 9.19 & 6.06 & 5.18 & 8.87 & 0.12 & 0.77 \\
& & SD & 3.74 & 3.64 & 3.08 & 3.26 & 0.12 & 0.10 \\
\hline
\end{tabular}

*Note: FW = fish weight (g/fish) 
Mathematical models for error estimation comparison results found no statistically significant differences between the whole body images and without fin images. Coefficient of determination from an average $\left(\mathrm{N}_{150} \mathrm{R}^{2}\right)$, showed a statistical difference $(\mathrm{P}<0.05)$ for without fin images at $0.77 \pm 0.10$, while whole body images with fins gave $0.24 \pm 0.20$. Coefficient of determination obtained from total validation $\left(\mathrm{N}_{600} \mathrm{R}^{2}\right)$ of the whole body images was 0.63 and without fin images was 0.96 , as shown in Table 4 and Figure 5.

Table 4 Comparison of error and $\mathrm{R}^{2}$ between models of fish whole body with fins and without fins.

\begin{tabular}{lccccccc}
\hline \multicolumn{1}{c}{ Fish shape } & RMSE (g) & MAE (g) & MARE (\%) & MXAE (g) & MXRE (\%) & $\mathbf{N}_{\mathbf{1 5 0}} \mathbf{R}^{\mathbf{2}}$ & $\mathbf{N}_{\mathbf{6 0 0}} \mathbf{R}^{\mathbf{2}}$ \\
\hline With fins & $12.35 \pm 4.45$ & $11.26 \pm 3.61$ & $9.69 \pm 2.94$ & $11.50 \pm 4.71$ & $0.14 \pm 0.11$ & $0.24 \pm 0.20^{\mathrm{b}}$ & 0.63 \\
Without fins & $9.19 \pm 3.74$ & $6.06 \pm 3.64$ & $5.18 \pm 3.08$ & $8.87 \pm 3.26$ & $0.12 \pm 0.12$ & $0.77 \pm 0.10^{\mathrm{a}}$ & 0.96 \\
\hline
\end{tabular}

*Note: Mean+standard deviation with different superscript letters in the same column are significantly different $(\mathrm{P}<0.05) ; \mathrm{N}_{150} \mathrm{R}^{2}=$ average coefficient of determination from the validation dataset generated from 15 fish (150 images) from every test, and $\mathrm{N}_{600} \mathrm{R}^{2}=$ average coefficient of determination from the total validation dataset generated from 60 fish (600 images) from all tests.

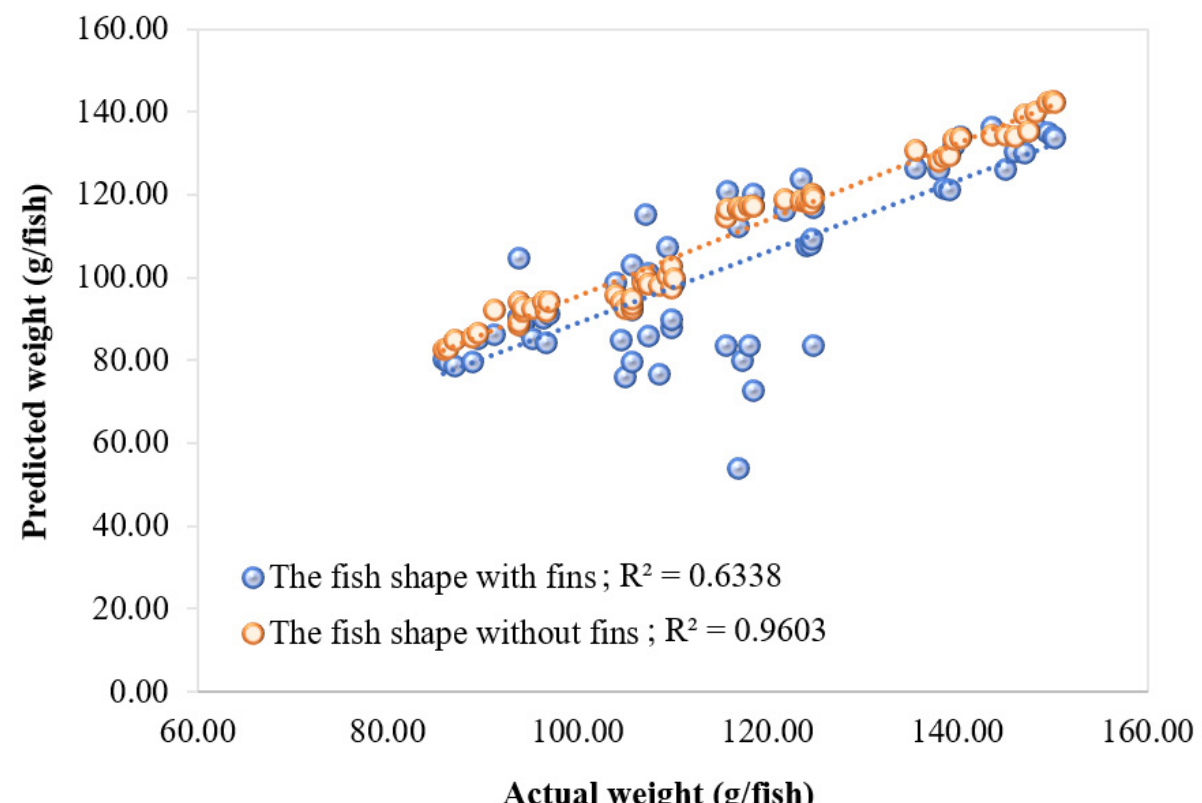

Figure 5 Coefficient of variation from total validation dataset between fish shape with fins and without fins.

The relationship between weight-to-image areas of the fish showed that the fish weight positively correlated with the image area of both whole body and without fins. As the weight of the fish increased, the image area of the fish also increased accordingly [9,10,17] (Figure 6).

The use of without fin images gave better predictive mean values compared to using the whole body images. This result was consistent with [9] who studied the use of image processing techniques to assess 
the weight of Jade Perch (Scortum barcoo). They commented that the fins of the fish had an uneven mass, resulting in differences in image processing techniques. [10] studied Asian sea bass (Lates calcarifer) and mentioned that the fins and tail of the fish were highly flexible and easily deformed during swimming (Figure 7), while damage often occurred during rearing and harvesting. [8] applied a full-body imageprocessing technique to assess the weight of salmon. Results showed that the whole fish image processing affected the image area and generated errors. They suggested that a program should be developed to process images by cutting out the areas of the fins and tail.

Previous studies have proved linear mathematical models to be more predictable, with fewer errors for estimating fish weight compared to power or polynomial models for grey mullet (Mugill cephalus), St. Peter's fish (Sarotherodon galilaeus), common carp (Cyprinus carpio) [14] and jade perch (Scortum barcoo) [9]. For large fish with mean size greater than $1,000 \mathrm{~g}$ during culture, it may be necessary to test using other mathematical models. For example, [10] used a power model to assess the weight of sea bass between 250 and 2,800 g. However, when comparing image formats with and without fins, linear modeling is considered sufficient.

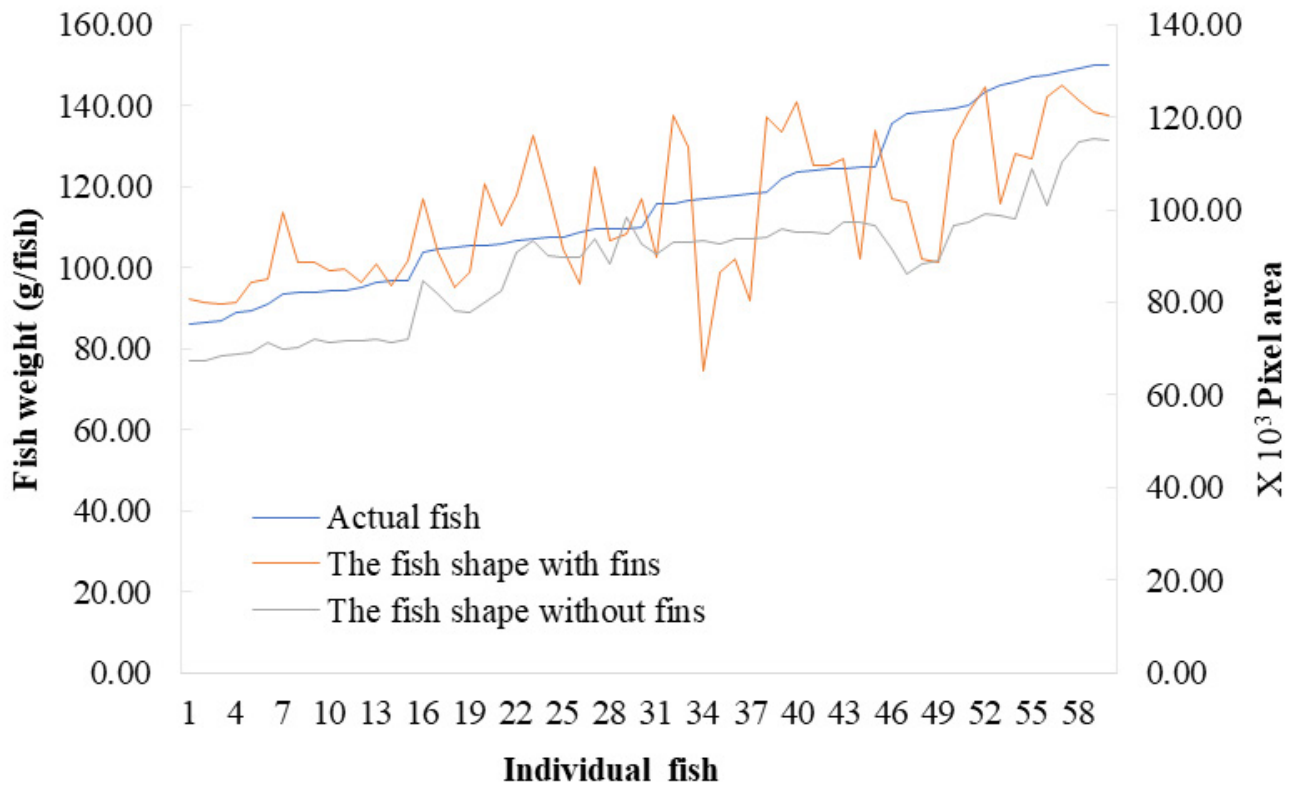

Figure 6 Relationship between weight-to-image areas. 

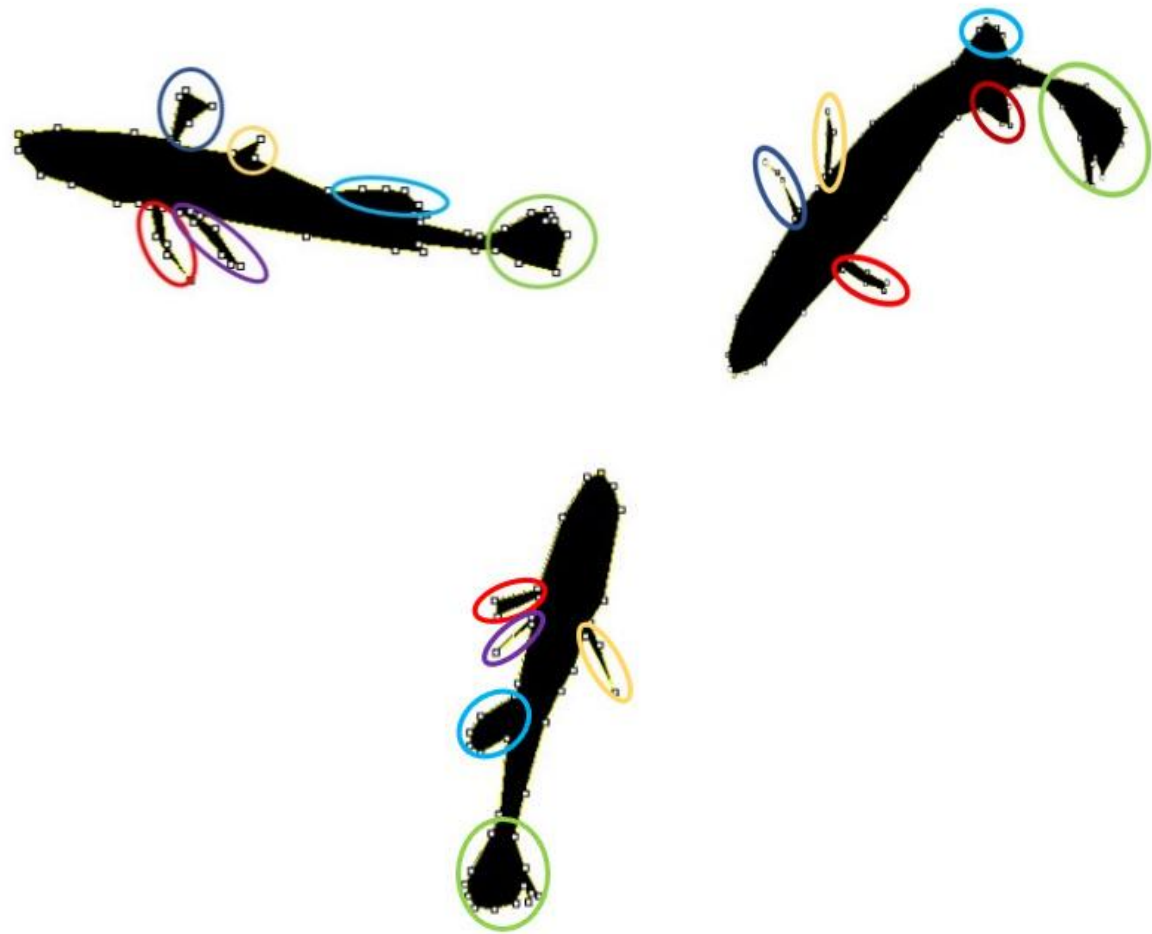

Figure 7 Binary images: differences of fish shape pixel area for fins of the same fish at different times.

\section{Weight error comparison between the image processing technique model and manual assessment \\ The results from all four tests showed that in the first test, the average manual fish weight} measurement was $92.23 \mathrm{~g}$, while using the whole body with fins model the average was 87.03, giving an average error of $5.20 \mathrm{~g}(5.64 \%)$. When using the model without fins, the predicted average weight was $89.74 \mathrm{~g}$, with an average error of $2.48 \mathrm{~g}(2.69 \%)$. In the second test, the average fish weight was 107.11 $\mathrm{g}$. When using the first model, the average weight was $93.28 \mathrm{~g}$ with average error of $13.83 \mathrm{~g}(12.91 \%)$, and when using the second model, the average weight was $94.70 \mathrm{~g}$ with average error of $9.87 \mathrm{~g}(9.21 \%)$. In the third test, the average fish weight was $120.33 \mathrm{~g}$. The weight evaluation using the first model was $110.09 \mathrm{~g}$ with an average error of $10.24 \mathrm{~g}(8.51 \%)$, and $117.80 \mathrm{~g}$ with an average error of $2.54 \mathrm{~g}(2.11 \%)$ when applying the second model. In the fourth test, the average fish weight was $143.85 \mathrm{~g}$. Using the first model gave $130.68 \mathrm{~g}$ with an average error of $13.17 \mathrm{~g}(9.15 \%)$, and using the second model gave 135.37 $\mathrm{g}$ with an average error of $8.48 \mathrm{~g}(5.89 \%)$. However, when comparing average values of both models of all four tests with average weight by the typical method, the results showed no significant difference $(\mathrm{P}>$ 0.05) (Table 5). 
Table 5 Comparison between hand measuring and image processing techniques.

\begin{tabular}{|c|c|c|c|c|c|c|c|c|}
\hline \multirow{3}{*}{ Test } & \multirow{3}{*}{$\begin{array}{c}\begin{array}{c}\text { Hand } \\
\text { measuring }\end{array} \\
\text { Fish } \\
\text { weight (g) }\end{array}$} & \multicolumn{7}{|c|}{ Image processing } \\
\hline & & \multicolumn{3}{|c|}{ Fish shape with fins } & \multicolumn{3}{|c|}{ Fish shape without fins } & \multirow[b]{2}{*}{ P-value } \\
\hline & & $\begin{array}{c}\text { Fish } \\
\text { weight (g) }\end{array}$ & $\begin{array}{c}\text { Error } \\
(\mathrm{g})\end{array}$ & $\begin{array}{c}\text { Error } \\
(\%)\end{array}$ & $\begin{array}{c}\text { Fish weight } \\
\text { (g) }\end{array}$ & $\begin{array}{c}\text { Error } \\
\text { (g) }\end{array}$ & $\begin{array}{c}\text { Error } \\
(\%)\end{array}$ & \\
\hline 1 & 92.23 & 87.03 & 5.20 & 5.64 & 89.74 & 2.48 & 2.69 & $>0.05$ \\
\hline 2 & 107.11 & 93.28 & 13.83 & 12.91 & 94.70 & 9.87 & 9.21 & $>0.05$ \\
\hline 3 & 120.33 & 110.09 & 10.24 & 8.51 & 117.80 & 2.54 & 2.11 & $>0.05$ \\
\hline \multirow[t]{3}{*}{4} & 143.85 & 130.68 & 13.17 & 9.15 & 135.37 & 8.48 & 5.89 & $>0.05$ \\
\hline & & & Mean & 9.05 & & & 4.98 & \\
\hline & & & SD & 2.99 & & & 3.28 & \\
\hline
\end{tabular}

The weight evaluation models using the whole area image processing technique with fins and without fins gave average errors of $9.05 \pm 2.99$ and $4.98 \pm 3.28 \%$, respectively. If considering only the fish shape without fins model, the error was similar to previous research results at less than $10 \%$. For example, [16] used a routine underwater camera method to assess the length of tuna raised in cages, while [17] applied this technique to assess the size of salmon in a light box and [6] used an underwater camera with Move-tr/3Dtm software to measure 3D length of Pacific bluefin tuna.

Our results suggested that computer vision techniques can be used to replace time-dependent manpower physical weighing that causes increased fish stress. The use of this model technique allows fish to continue swimming freely in the water during weight measurement.

\section{Conclusions}

The results showed that $2 \mathrm{D}$ computer vision techniques can be used to select the appropriate without fin image model to generate an algorithm that can accurately estimate the mass of Asian sea bass (Lates calcarifer) by measuring the area of the fish from top view. Fish shape without fins showed comparable results $(\mathrm{RMSE}=9.19 \pm 3.74 \mathrm{~g}, \mathrm{MAE}=6.06 \pm 3.64 \mathrm{~g}, \mathrm{MARE}=5.18 \pm 3.08 \%, \mathrm{MXAE}=8.87 \pm 3.26 \mathrm{~g}$, $\left.\mathrm{MXRE}=0.12 \pm 0.12 \%, \mathrm{~N}_{15} \mathrm{R}^{2}=0.77 \pm 0.10, \mathrm{~N}_{60} \mathrm{R}^{2}=0.96\right)$ to fish shape with fins (RMSE $=12.35 \pm 4.45$ $\mathrm{g}, \mathrm{MAE}=11.2 \pm 3.61 \mathrm{~g}, \mathrm{MARE}=9.69 \pm 2.94 \%$, MXAE $=11.50 \pm 4.71 \mathrm{~g}, \mathrm{MXRE}=0.14 \pm 0.11 \%$, $\mathrm{N}_{150} \mathrm{R}^{2}=0.24 \pm 0.20, \mathrm{~N}_{600} \mathrm{R}^{2}=0.63$ ). The area of the fish was sufficient to predict the mass. This model represents the first step toward development of an automatic monitoring tool that can estimate fish weight when the fish is swimming freely in the water.

\section{Acknowledgements}

The authors are grateful to the Department of Aquaculture, Faculty of Fisheries, Kasetsart University for supporting laboratory operations and to Mr. Krisada Phromsuthirak (Currently pursuing a D.Eng. Degree in Electrical Engineering) from the Department of Electrical Engineering, Faculty of Engineering, Kasetsart University for providing us a piece of engineering advice. 


\section{References}

[1] Department of Fisheries. Fishery statistical analysis and research ground. Information and Communication Technology Center, Department of Fisheries, 2019.

[2] AD Pickering and P Christie. Changes in the concentrations of plasma-cortisol and thyroxine during sexual-maturation of the hatchery-reared brown trout, Salmo trutta L. Gen. Comp. Endocrinol. $1981 ; 44,487-96$.

[3] GW Klontz. Producing a marketable fish. Part V. Inventory techniques. North. Aquac. 1993; 10, 215.

[4] TA Beddow, LG Ross and JA Marchant. Predicting salmon biomass remotely using a digital stereoimaging technique. Aquaculture 1996; 146, 189-203.

[5] NK Newlands and TA Porelli. Measurement of the size, shape and structure of Atlantic bluefin tuna schools in the open ocean. Fish. Res. 2008; 91, 42-55.

[6] S Torisawa, M Kadota, K Komeyama, K Suzuki and T Takagi. A digital stereo-video camera system for three-dimensional monitoring of free-swimming pacific bluefin tuna, Thunnus orientalis, cultured in a net cage. Aquat. Living Resour. 2011; 24, 107-12.

[7] JM Miranda and M Romero. A prototype to measure rainbow trout's length using image processing. Aquacult. Eng. 2017; 76, 41-9.

[8] MO Balaban, GFÜ Sengor, MG Soriano and EG Ruiz. Using image analysis to predict the weight of Alaskan salmon of different species. J. Food. Sci. 2010; 75, 157-62.

[9] S Viazzi, SV Hoestenberghe, B Goddeeris and D Berckmans. Automatic mass estimation of jade perch Scortum barcoo by computer vision. Aquacult. Eng. 2015; 64, 42-8.

[10] DA Konovalov, A Saleh, JA Domingos, RD White, DR Jerry. Estimating mass of harvested Asian seabass Lates calcarifer from images. World J. Eng. Tech. 2018; 6, 15-23.

[11] GS Jamerlan and RM Coloso. Intensive culture of seabass Lates calcarifer Bloch, in brackish water Earthen ponds. Southeast Asian Fisheries Development Center, Aquaculture Department, Tigbanan, Iloilo, Philippines, 2010.

[12] JA Madrones-Ladja and MR Catacutan. Net cage rearing of the Asian seabass Lates calcarifer (Bloch) in brackish water Pond. Philipp. Aqric. Sci. 2012; 95, 79-86.

[13] ImageJ, Available at: http://imageJ.nih.gov/ij/, accessed September 2019.

[14] B Zion. The use of computer vision technologies in aquaculture: A review. Comput. Electron. Agr. $2012 ; \mathbf{8 8}, 125-32$.

[15] AFA Fernandes, EM Turra, ERD Alvarenga, TL Passafaro, FB Lopes, GFO Alves, V Singh, GJM Rosa. Deep learning image segmentation for extraction of fish body measurements and prediction of body measurements and prediction of body weight and carcass traits in Nile tilapia. Comput. Electron. Agric. 2020; 170, 105274.

[16] C Costa, F Antonucci, C Boglione, P Menesatti, M Vandeputte and B Chatain. Automated sorting for size, sex and skeletal anomalies of cultured seabass using external shape analysis. Aquacult. Eng. 2013; 52, 58-64.

[17] E Misimi, U Erikson and A Skavhaug. Quality grading of Atlantic salmon (Salmo salar) by computer vision. J. Food. Sci. 2008; 73, 211-7. 